\title{
Partial Purine Deprivation Causes Sporulation of Bacillus subtilis in the Presence of Excess Ammonia, Glucose and Phosphate
}

\author{
By E. FREESE, J. E. HEINZE* AND E. M. GALLIERS \\ Laboratory of Molecular Biology, National Institute of Neurological and Communicative \\ Disorders and Stroke, National Institutes of Health, Bethesda, Maryland 20014, U.S.A.
}

(Received 8 March 1979)

\begin{abstract}
In strains of Bacillus subtilis able to synthesize purines de novo, massive sporulation is suppressed by the combination of excess ammonia, glucose and phosphate. Purine auxotrophs, blocked in the general or the guanine-specific portion of the branched purine pathway, sporulated in such a medium when the purine required for normal growth was removed from the medium. The resulting spore titre and the sporulation frequency increased with the residual growth rate in the purine-free medium, i.e. with the leakiness of the purine mutation. Sporulation was further increased by allowing residual growth in growth-limiting amounts of guanosine. Non-leaky purine mutants blocked before 5'-phosphoribosyl-5amino-4-imidazole carboxamide also sporulated well when supplied with 5-amino-4imidazole carboxamide at concentrations $(2 \mathrm{~mm})$ that supported growth at a suboptimal rate.
\end{abstract}

\section{INTRODUCTION}

Massive production of heat-resistant endospores is usually observed about $8 \mathrm{~h}$ after cells of the genus Bacillus are placed in an environment from which phosphate has been exhausted or in which the carbon or the nitrogen source is so slowly utilized that polymer synthesis (cell growth) can continue only at a very low rate (Schaeffer, 1969; Hanson et al., 1970). Many other micro-organisms also differentiate under such conditions. It has been demonstrated, by the use of inhibitors or mutants blocked in known enzymes, that sporulation of Bacillus subtilis requires a much more precise metabolic balance than does growth; it is prevented by the intracellular accumulation of any organic acid (Freese et al., 1974) or by the action of certain inhibitors of nucleic acid or protein synthesis (Bohin et al., 1976; Rogolsky \& Nakamura, 1974; Keilman et al., 1976; Rhaese et al., 1977; Burke \& Spizizen, 1977). Another attempt to identify compounds controlling sporulation utilized the fact that sporulation remains suppressed in the presence of rapidly metabolizable carbohydrates (e.g. glucose), nitrogen sources (e.g. ammonium ions) and phosphate. Mutants were isolated which can sporulate more or less well in the presence of these nutrients (Levisohn \& Aronson, 1967; Ito \& Spizizen, 1973; Kunst et al., 1974); strains that sporulated particularly efficiently were usually purine auxotrophs. In $B$. megaterium, all such auxotrophs were blocked in the early purine pathway, before 5'-phosphoribosyl-5-aminoimidazole (AIR) (Elmerich \& Aubert, 1975) (see Fig. 1). Therefore, Elmerich \& Aubert (1975) proposed that the accumulation of an early intermediate in the purine pathway may initiate sporulation, perhaps by binding to glutamine synthetase (see also Reysset \& Aubert, 1975). Attempts injour laboratory to obtain significant sporulation of such an early-blocked purine mutant of $B$. subtilis in

* Present address: Dial Microbiology Group, Armour Research Center, Scotsdale, Arizona 85260, U.S.A. 
the absence of purine were unsuccessful (Freese et al., 1974). This apparent discrepancy could be explained by a hypothesis of asymmetric prespore septation, which assumes that RNA and protein synthesis have to be reduced but not completely stopped while membrane synthesis has to continue in order for asymmetric septation and thus sporulation to occur (Freese, 1976). If this were correct, only leaky mutations allowing a reduced rate of RNA and protein synthesis would sporulate well after removal of purine. In agreement with (but not proof of) this hypothesis, subsequent experiments demonstrated that inhibitors of purine nucleotide synthesis could induce sporulation but only if they were used at concentrations that only partially inhibited growth (and thus purine synthesis) (Mitani et al., 1977; Freese et al., 1978; Heinze et al., 1978). Many other inhibitors (of nucleic acid or protein synthesis) did not show sporulation induction at any concentration (Heinze et al., 1978).

Observations made using inhibitors invite the criticism that they might be the result of inhibition of some reaction different from that studied. Therefore, we have tried to demonstrate that sporulation can also be initiated in purine auxotrophs by the partial deprivation of purine nucleotides and that this initiation is not restricted to a block before AIR. Two approaches were used. (1) A large number of purine auxotrophs, isolated in various laboratories, were tested for their ability to sporulate after removal of purine; the sporulation frequency was correlated with the residual growth of the mutant, i.e. its leakiness. (2) Some purine auxotrophs were transferred to media containing different concentrations of a precursor of purine nucleotides; the subsequent sporulation was optimal at an intermediate concentration of the precursor. Both approaches demonstrated that sporulation is initiated by conditions under which the synthesis of purine-, in particular of guanine-, nucleotides is reduced but not completely inhibited.

\section{METHODS}

Abbreviations. AICA, 5-amino-4-imidazole carboxamide; AICAR, 5'-phosphoribosyl-5-amino-4-imidazole carboxamide; AIR, 5'-phosphoribosyl-5-aminoimidazole; PRPP, 5-phosphoribosylpyrophosphate.

Bacteria. The origin and auxotrophic properties of the strains of $B$. subtilis used in this work are listed in Table 1. Transformation was performed as previously described (Iijima et al., 1977).

Media. A synthetic medium was used which contained $10 \mathrm{mM}$ - $\left(\mathrm{NH}_{4}\right)_{2} \mathrm{SO}_{4}, 5 \mathrm{~mm}$-potassium phosphate (pH 7.0), $100 \mathrm{~mm}$-morpholinopropanesulphonate (adjusted to $\mathrm{pH} 7$ with $\mathrm{NaOH}$ ), $2 \mathrm{mM}-\mathrm{MgCl}_{2}, 0.7 \mathrm{~mm}$ $\mathrm{CaCl}_{2}, 50 \mu \mathrm{M}-\mathrm{MnCl}_{2}, 5 \mu \mathrm{M}-\mathrm{FeCl}_{3}, 1 \mu \mathrm{M}-\mathrm{ZnCl}_{2}, 2 \mu \mathrm{M}$-thiamin, and the stated amounts of D-glucose and L-glutamate (adjusted to $\mathrm{pH} 7 \cdot 0$ with $\mathrm{KOH}$ ) as carbon sources. (Bacillus subtilis metabolizes glucose rapidly and glutamate very slowly.) Added to this medium were the compounds required by auxotrophs (each at $50 \mu \mathrm{g} \mathrm{ml}^{-1}$ ) except where otherwise stated. Adenine, AICA, guanine, guanosine, hypoxanthine and xanthine stock solutions were prepared in dilute $\mathrm{KOH}$.

Growth conditions. All strains were grown for $7 \mathrm{~h}$ at $37^{\circ} \mathrm{C}$ on plates containing tryptose blood agar base (TBAB, $33 \mathrm{~g} \mathrm{l}^{-1}$; Difco) plus the required purine $\left(50 \mu \mathrm{g} \mathrm{ml}^{-1}\right)$. The cells were then inoculated at different low cell titres $\left(A_{600} 10^{-5}\right.$ to $\left.10^{-4}\right)$ into three flasks containing synthetic medium plus any required compound (each at $50 \mu \mathrm{g} \mathrm{ml}^{-1}$ ); these precultures were shaken overnight at $37^{\circ} \mathrm{C}$. When the $A_{600}$ of one culture reached 0.4 to 0.5 , the cells were collected by filtration through membrane filters $(25 \mathrm{~mm}$ diam., $0.47 \mu \mathrm{m}$ pore size; Millipore), immediately washed with an equal amount of warm synthetic medium lacking the required purine and glucose, and resuspended using a vortex mixer in this medium plus glucose; $10 \mathrm{ml}$ samples were distributed into warm $\left(37^{\circ} \mathrm{C}\right) 125 \mathrm{ml}$ flasks containing various amounts of the required purine and incubated at $37^{\circ} \mathrm{C}$ with vigorous shaking. Growth was monitored by measuring the $A_{600}$ of the cultures (diluted in synthetic medium without carbon source). The total viable cell titre (V) was determined by diluting the culture in synthetic medium without carbon source and plating on TBAB plates. Spore titre (S) was measured by heating the diluted culture for $20 \mathrm{~min}$ at $75^{\circ} \mathrm{C}$ and then plating. Spore and viable cell titres were usually determined $10 \mathrm{~h}$ after transfer to the new medium. Glucose, ammonia and phosphate were assayed as previously described (Mitani et al., 1977).

For the determination of spore yields under normal sporulation conditions (Table 2, column 3), overnight cultures on TBAB plates containing the required purine $\left(50 \mu \mathrm{g} \mathrm{ml}^{-1}\right)$ were inoculated into synthetic medium containing $14 \mathrm{mM}$-glucose, $10 \mathrm{mM}$-L-glutamate, the required amino acids (each $50 \mu \mathrm{g} \mathrm{ml}^{-1}$ ) and the required purine $\left(50 \mu \mathrm{g} \mathrm{ml}^{-1}\right)$ (plus $100 \mu \mathrm{g}$ hypoxanthine $\mathrm{ml}^{-1}$ in the case of purine double mutants), to give an $A_{600}$ of 0.02 to 0.05 . Cultures $(2 \mathrm{ml})$ were then grown at $37^{\circ} \mathrm{C}$ in $25 \mathrm{~mm}$ diam. tubes with vigorous aeration. In this medium, all glucose was used within $8 \mathrm{~h}$; spore and viable cell titres were determined after $24 \mathrm{~h}$. 
Table 1. Origin and characteristics of the Bacillus subtilis strains used

Strain Genotype*

Purine prototrophs used in strain construction

$\begin{array}{ll}60001 & \text { trpC2 } \\ 60009 & \text { prototroph } \\ 60015 & \text { metC7 trpC2 } \\ 61469 & \text { lys-3 metB10 trpC2 } \\ 61508 & \text { hisA1 leu-8 lys-1 metB5 trpC3 }\end{array}$

Purine auxotrophs

$\begin{array}{ll}60016 & \text { Pur trpC2 } \\ 60017 & \text { his Pur trpC2 } \\ 60074 & \text { hisB Pur trpC2 } \\ 60173 & \text { Pur } \\ 60174 & \text { Pur } \\ 60247 & \text { leu-8 metB5 PurB6 } \\ 61232 & \text { Pur-1 trpC2 } \\ 61305 & \text { Pur } \\ & \\ 61306 & \text { GuaA Pur } \\ 61307 & \text { GuaB Pur } \\ 61308 & \text { Ade Phe } \\ 61493 & \text { Pur-34 } \\ 61509 & \text { adeA16 hisA1 leu-8 met B5 trpC2 } \\ 61553 & \text { adeA16 leu-8 lys-21 metB5 } \\ 61637 & \text { metC7 Pur trpC2 } \\ 61639 & \text { metC7 purH1 trpC2 } \\ 61676 & \text { guaA3 metC7 purH1 trpC2 } \\ 61677 & \text { guaB2 metC7 purH1 trpC2 } \\ 61685 & \text { Ade metC7 pur trpC } \\ 61716 & \text { metB5 pur trpC2 } \\ 61719 & \text { met B5 pur trpC2 }\end{array}$

\begin{tabular}{cl}
$\begin{array}{c}\text { Purine mutant } \\
\text { class } \dagger\end{array}$ & \multicolumn{1}{c}{ Origin $\ddagger$} \\
& \\
+ & 168, J. Spizizen \\
+ & 60001 Trp \\
+ & SB26, E. Nester \\
+ & BR151, R. Young \\
+ & J. Iijima
\end{tabular}

SB23, E. Nester

SB4, E. Nester

S. Greer

$60009+\mathrm{UV}$

$60009+U V$

Mu8u5u6, N. Sueoka

$\mathrm{Br} 5$, B. Reiley

MB1356, A. Demain (Demain \&

Shigeura, 1968)

MB1358, A. Demain (as above)

MB1517, A. Demain (as above)

MB1364, A. Demain (as above)

Mu34, N. Sueoka

Tf of 61508 by 61553

BD46, D. Dubnau

$60015+$ EMS

$60015+$ EMS

$61639+$ EMS

$61639+$ EMS

$61639+$ EMS

Tf of 61469 by 61639

Tf of 61469 by 61637

* Standard B. subtilis genetic symbols are used (Young \& Wilson, 1975). In addition Ade, Gua and Pur indicate, respectively, requirements for adenine, for guanine ( $\mathrm{GuaA}$ can also grow on xanthine while GuaB cannot), and for adenine, guanine, xanthine or hypoxanthine. Where the three-letter abbreviation of an auxotrophic requirement begins with a capital, the genetic map location of the mutation is not known.

$\dagger$ Classes as in Fig. 1.

¥ UV and EMS indicate, respectively, mutagenesis with ultraviolet light and ethyl methanesulphonate. Tf means transformation of the first strain by DNA of the second strain.

Biochemical classification of purine auxotrophs. Mutations affecting the purine pathway were classified as described by Magasanik (1962) and shown in Fig. 1. Mutants of class 1, blocked before the synthesis of IMP, could grow on adenine, hypoxanthine, xanthine or guanine as a purine source due to the interconversion of AMP and GMP via IMP. Class 2 mutants responded to xanthine or guanine, class 3 mutants responded only to guanine, while class 4 mutants responded only to adenine. Class 1 mutants could be further subdivided by their ability to grow on AICA as a purine source (class 1a or 1b) and to excrete AICA (class 1c) or AIR (class 1b). The latter two compounds were determined by a colorimetric assay (Bratton \& Marshall, 1939) after overnight growth on limiting hypoxanthine $\left(5 \mu \mathrm{g} \mathrm{ml} l^{-1}\right)$.

The Gua mutants 61306 and 61307 were shown to have an additional Pur mutation in the general purine pathway since no Gua independent mutations could be found on plates of synthetic medium without any purine while they were observed on plates of synthetic medium containing hypoxanthine or adenine. The revertants required hypoxanthine (or adenine or guanine) for growth. All double mutants (Gua Pur) could grow on guanine as sole purine source because they contained GMP reductase converting GMP into IMP. Similarly the Ade Pur double mutant could grow on adenine as sole purine source because it rapidly converted adenine to hypoxanthine as was established by hypoxanthine measurements in the medium (see below).

Assay of guanosine, hypoxanthine etc. Guanosine, guanine etc. were assayed in the growth medium, after removal of cells by rapid $(1 \mathrm{~min})$ centrifugation, according to Coddington (1970). This assay measures the sum of guanine, hypoxanthine, xanthine and their ribosides. When guanase is omitted only hypoxanthine, xanthine and their nucleosides are detected, and when nucleoside phosphorylase is also omitted only hypoxanthine and xanthine are detected. The increase of hypoxanthine or xanthine could therefore be directly assayed and the decrease of guanosine (and guanine) could be measured by the difference between the results 


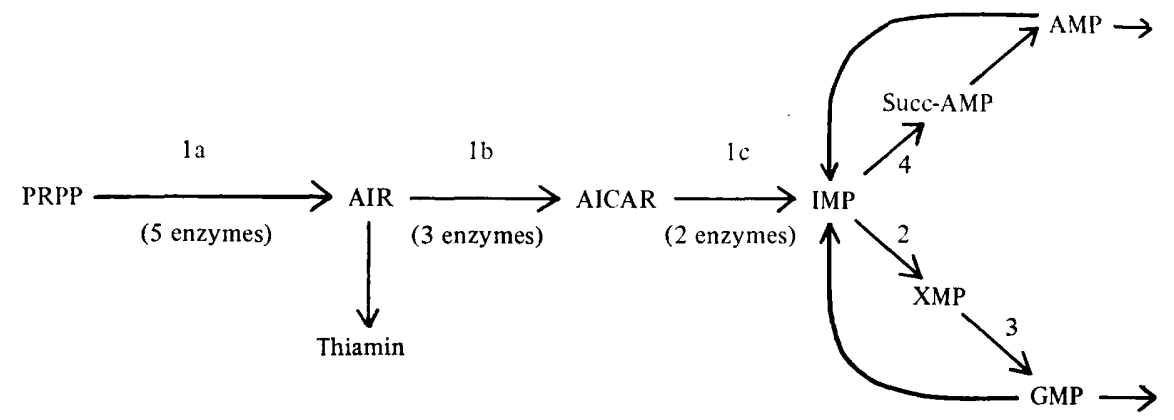

Fig. 1. Purine biosynthetic pathway showing the classification of purine auxotrophs. Abbreviations: PRPP, D-5-phosphoribosylpyrophosphate; AIR, 5'-phosphoribosyl-5-aminoimidazole; AICAR, 5'-phosphoribosyl-5-amino-4-imidazole carboxamide; IMP, inosine 5'-phosphate; XMP, xanthosine 5'-phosphate; GMP, guanosine 5'-phosphate; AMP, adenosine 5'-phosphate; Succ-AMP, adenylosuccinate.

obtained with and without guanase. Guanosine and guanine could not be distinguished in this assay because the guanase preparation used (Boehringer Mannheim) contained nucleoside phosphorylase. Hypoxanthine and xanthine were separately determined according to Jorgensen (1970).

The dissimilation of $\left[\mathrm{U}_{-14}{ }^{14} \mathrm{C}\right] \mathrm{guanosine}$ and $\left[8{ }^{14} \mathrm{C}\right)$ guanine $\left(50 \mu \mathrm{M}, 1.67 \mu \mathrm{Ci} \mathrm{ml}{ }^{-1}\right)$ was measured in synthetic medium containing $55 \mathrm{~mm}$-glucose, $20 \mathrm{~mm}$-sodium glutamate, $0 \cdot 1 \%$ (w/v) casein hydrolysate and $100 \mu \mathrm{g}$ hypoxanthine $\mathrm{ml}^{-1}$. Strain 61676 was grown in this medium containing $1 \mathrm{~mm}$ (non-radioactive) guanosine until the $A_{600}$ was 0.5 . The cells were washed on membrane filters in guanosine-free medium and suspended in $15 \mathrm{ml}$ of the radioactive medium. At different times, $0.8 \mathrm{ml}$ samples were taken, the $A_{600}$ was measured and the cells were removed by centrifugation in an Eppendorf microfuge. Samples $(5 \mu \mathrm{l})$ of each supernatant were applied (alone or with purine standards) to thin-layer plastic sheets $(20 \times 20 \mathrm{~cm})$ covered with polyethyleneimine cellulose $(0.1 \mathrm{~mm}$ thick, Polygram CEL300 PEI; Macherey-Nagel) which had been washed for 10 min each with $\mathrm{H}_{2} \mathrm{O}, 10 \%$ (w/v) $\mathrm{NaCl}, \mathrm{H}_{2} \mathrm{O}, 0.5$ M-potassium phosphate (pH 3.4), $\mathrm{H}_{2} \mathrm{O}$ and again $\mathrm{H}_{2} \mathrm{O}$. The sheets were eluted with $20 \mathrm{~mm}$-potassium phosphate buffer $(\mathrm{pH} 7 \cdot 0)$ for $2 \mathrm{~h}$. The relative elution sequence (from front to origin) was inosine $>$ hypoxanthine $\geqslant$ guanosine $>$ xanthine $>$ guanine. After autoradiography for $3 \mathrm{~d}$ with X-omat $\mathbf{R} \mathrm{X}$-ray film (Kodak) the radioactive spots were cut out (using a soldering iron with a thin hot copper tip) and counted in $10 \mathrm{ml}$ Aquasol (New England Nuclear) in a scintillation counter.

\section{RESULTS}

\section{Characterization of purine auxotrophs}

We had previously isolated six independent mutants of $B$. subtilis able to sporulate well after transfer (at $A_{600} 0 \cdot 5$ ) from a rich medium (containing amino acids, vitamins, purines and pyrimidines) to a minimal medium containing excess ammonia, glucose and phosphate. All six mutants were purine auxotrophs; three were blocked before AIR and three after it. Realizing the prevalence of purine mutants among the auxotrophs able to sporulate under these conditions, we investigated systematically the sporulation properties of all independently isolated purine auxotrophs of $B$. subtilis available to us.

The origin of the different purine auxotrophs is given in Table 1. For some mutants, specifically indicated, the purine marker was transferred by DNA transformation into another strain in order to ascertain that the ability to sporulate as a result of purine deficiency transformed with the purine marker. Some adenine- or guanine-requiring mutants had a second mutation in the general purine pathway. The Ade Pur double mutants (for nomenclature, see Table 1) could grow with adenine or adenosine and the Gua Pur double mutants could grow with guanine or guanosine as sole purine source. Nevertheless, hypoxanthine $\left(100 \mu \mathrm{g} \mathrm{ml}^{-1}=735 \mu \mathrm{M}\right)$ was always added to satisfy the general purine requirement caused by the Pur mutation and adenine or guanine was added (or omitted) to satisfy (or to starve for) the specific requirements of the Ade or Gua mutation. 
The purine pathway can be subdivided into groups of reactions (Fig. 1) whose biochemical block in a purine auxotroph can be relatively easily identified, as has been shown by Magasanik (1962). The classification of the mutants used here (Table 1) was determined by the excretion of AIR or AICAR and by the growth response on feeding AICA, hypoxanthine, adenine, xanthine or guanine.

The genetic constitution of each mutant, apart from the purine marker, determines to what extent the mutant can sporulate at all. Therefore, 'normal' sporulation (following exhaustion of glucose) was first measured in the presence of the required purine using a synthetic medium similar to that subsequently employed for the determination of sporulation during purine deficiency but containing less glucose $(14 \mathrm{~mm})$; this medium also contained $10 \mathrm{~mm}$-glutamate which served as a slowly metabolizable carbon source after glucose was used up at the end of growth. [The need for a slowly metabolizable carbon source for the normal sporulation of $B$. subtilis has been well established (Ramaley \& Burden, 1970; Sugae \& Freese, 1970).] The standard pur ${ }^{+}$strains (e.g. 60015) sporulated after the end of growth in this medium (measured after $24 \mathrm{~h}$ ) (see Table $2 ; \mathrm{S} / \mathrm{V}=0 \cdot 3$ ). Three mutants that could not produce at least $10^{7}$ spores $\mathrm{ml}^{-1}$ in this medium and could also not sporulate well in the absence of purines were not used for further experiments; it was assumed (but not checked by genetic transfer) that these mutants contained other mutations (unrelated to the purine marker) which prevented normal sporulation. Other exceptions were strains 61716 and 61719; they sporulated poorly in the presence of purines, a property of their parent 61469, but at a high frequency in the absence of purines (Table 2). All other mutants listed in Table 2 produced at least $10^{7}$ spores $\mathrm{ml}^{-1}$ following growth in the low glucose (plus glutamate) medium while the required purine was present (Table 2 , column 3 ). To our knowledge, all the mutants listed in Table 2 contained different, independently isolated, mutations in the purine pathway.

\section{Growth and sporulation after removal of purine}

All mutants were grown in synthetic medium containing excess ammonia ( $20 \mathrm{~mm})$, glucose $(55 \mathrm{~mm})$, phosphate $(5 \mathrm{~mm})$ and the required purine adenine, hypoxanthine or guanine (each $50 \mu \mathrm{g} \mathrm{ml}^{-1}$ ) (for the adenine and guanine auxotrophs, $100 \mu \mathrm{g}$ hypoxanthine $\mathrm{ml}^{-1}$ was also present). When the $A_{600}$ reached 0.5 , the cells were washed and suspended in the same medium (with or without the required purine), and the resulting cultures were shaken at $37{ }^{\circ} \mathrm{C}$. The result of a typical growth and sporulation experiment is shown in Fig. 2. After removal of purine (time $t_{0}$ ), the $A_{600}$ of this particular strain continued to increase slowly and a significant number of cells sporulated. The hypoxanthine-containing culture produced no additional spores for $12 \mathrm{~h}$ after purine removal $\left(t_{12}\right)$ and showed only a small increase in spore titre at $t_{24}$. The concentrations of ammonia and phosphate were still greater than half the initial concentrations up to $t_{24}$. Glucose was used more rapidly but was still present ( $30 \mathrm{~mm}$ without and $2 \mathrm{mM}$ with hypoxanthine) at $t_{8}$ and was exhausted in the hypoxanthine-free culture only after $t_{12}$. Similar observations were made for all mutants containing independently isolated Pur mutations. Table 2 shows their residual growth after transfer to the purine-free medium, as well as the vegetative cell and spore titres at $t_{10}$ (columns 4,5 and 6 ). In the presence of purines all the strains grew at about the same rate $\left(0.7\right.$ to 0.8 doublings $\left.h^{-1}\right)$, but the extent of their residual growth after the removal of the required purine differed greatly (Table 2 ). The spore titres at $t_{10}$ in the presence of excess purines were less than $5 \times 10^{5} \mathrm{ml}$ for all mutants (except 61305, 61307, 61676 and 61677 - see below). They were significantly higher in the absence of the required purine, demonstrating the initiation of sporulation by removal of purine (Table 2). (For the Ade or Gua mutants that had a second mutation in the general purine pathway, sporulation was measured with and without added hypoxanthine with essentially the same result.) It is apparent from Table 2 that different mutants sporulated to greatly different degrees. There was no correlation between the spore titres observed in the absence of the required purine (in high glucose) and those observed in the presence of purines 
Table 2. Growth and sporulation of purine auxotrophs

\begin{tabular}{|c|c|c|c|c|c|}
\hline \multirow[b]{2}{*}{$\begin{array}{l}\text { Purine mutant } \\
\text { class }\end{array}$} & \multirow[b]{2}{*}{ Strain } & \multirow{2}{*}{$\begin{array}{c}\text { Purine present* } \\
\text { (14 mm-glucose) } \\
10^{-6} \times \text { Spore } \\
\text { titre }\end{array}$} & \multicolumn{3}{|c|}{ Purine absent $\uparrow$ (55 mM-glucose) } \\
\hline & & & $\begin{array}{c}\text { Residual } \\
\text { growth } \\
(\Delta A / A) \ddagger\end{array}$ & $\begin{array}{c}10^{-6} \times \text { Spore } \\
\text { titre }\end{array}$ & $\begin{array}{c}10^{-6} \times \text { Viable } \\
\text { cell titre }\end{array}$ \\
\hline 1a & $\begin{array}{l}60074 \\
60173 \\
60174 \\
60247\end{array}$ & $\begin{array}{r}70 \\
60 \\
54 \\
150\end{array}$ & $\begin{array}{l}0.61 \\
0.44 \\
0.54 \\
0.44\end{array}$ & $\begin{array}{l}480 \\
655 \\
450 \\
302\end{array}$ & $\begin{array}{c}82 \\
8 \cdot 9 \\
59 \\
50\end{array}$ \\
\hline $1 b$ & $\begin{array}{l}60016 \\
61232 \\
61493\end{array}$ & $\begin{array}{r}55 \\
49 \\
100\end{array}$ & $\begin{array}{l}0.53 \\
0.47 \\
0.64\end{array}$ & $\begin{array}{r}488 \\
91 \\
467\end{array}$ & $\begin{array}{l}2 \cdot 8 \\
2 \cdot 3 \\
36\end{array}$ \\
\hline 1c & $\begin{array}{l}60017 \\
61305 \\
61716 \\
61719\end{array}$ & $\begin{array}{c}66 \\
360 \\
1 \cdot 3 \\
3 \cdot 1\end{array}$ & $\begin{array}{l}0.81 \\
0.86 \\
0.50 \\
0.50\end{array}$ & $\begin{array}{l}570 \\
426 \\
318 \\
400\end{array}$ & $\begin{array}{c}200 \\
177 \S \\
55 \\
105\end{array}$ \\
\hline 2 & 61306 & 470 & 0.53 & 570 & 31 \\
\hline 3 & $\begin{array}{l}61307 \\
61677\end{array}$ & $\begin{array}{l}460 \\
340\end{array}$ & $\begin{array}{l}1 \cdot 15 \\
1.02\end{array}$ & $\begin{array}{l}106 \\
490\end{array}$ & $\begin{array}{l}118 \S \\
167 \S\end{array}$ \\
\hline 4 & $\begin{array}{l}61308 \\
61509 \\
61685\end{array}$ & $\begin{array}{c}120 \\
10 \\
2 \cdot 0\end{array}$ & $\begin{array}{l}0.016 \\
0.35 \\
0.00\end{array}$ & $\begin{array}{c}58 \\
247 \\
8.5\end{array}$ & $\begin{array}{l}0.041 \\
0.51 \\
0.00\end{array}$ \\
\hline prototroph & 60015 & 130 & $0 \cdot 774$ & 300 & $0 \cdot 10$ \\
\hline
\end{tabular}

* Strains were inoculated at $A_{600}=0.05$ into synthetic medium containing $14 \mathrm{~mm}$-glucose, $10 \mathrm{~mm}$ potassium L-glutamate and the required amino acids and purine (each $50 \mu \mathrm{g} \mathrm{ml}^{-1}$ ) (plus $100 \mu \mathrm{g}$ hypoxanthine $\mathrm{ml}^{-1}$ for mutants of classes 2,3 and 4).

$\dagger$ Strains were inoculated at $A_{600} \leqslant 0.05$ into synthetic medium containing $55 \mathrm{~mm}$-glucose and the required amino acids and purine (each $50 \mu \mathrm{g} \mathrm{ml}^{-1}$ ) (plus $100 \mu \mathrm{g}$ hypoxanthine $\mathrm{ml}^{-1}$ for mutants of classes 2,3 and 4). When the $A_{600}$ reached $0 \cdot 5$, cells were washed on membrane filters with medium lacking purine and resuspended in that medium (for mutants of classes 2,3 and 4 the medium also contained $100 \mu \mathrm{g}$ hypoxanthine $\mathrm{ml}^{-1}$ ). The numbers represent averages of two to four experiments; the mean deviation was usually less than a factor of 3 .

$\ddagger$ Increase of $A_{800}$ in $3 \mathrm{~h}$ after removal of purine $(\Delta A)$ divided by the $A_{600}$ immediately after resuspension.

$\S$ This mutant sporulated even in the presence of the required purine(s). But the cultures of mutants in class 2 or 3 that had been transferred at $A_{600}=0.5$ to a guanine-free medium showed a massive increase in their spore titre $2 \mathrm{~h}$ earlier.

after glucose (14 mM) had been used up. However, there was a good correlation between the spore titres and the residual growth observed after removal of purine (Fig. 3). In fact, the correlation was surprisingly good considering the different genetic constitution (apart from the purine marker) of the different mutants (as demonstrated by the differences in their sporulation frequencies under 'normal' sporulation conditions).

The ability to sporulate after removal of purine was not limited to mutations in a certain portion of the purine pathway. Some mutations in steps 1a, 1b, 1c, 2 and 3 allowed good sporulation. Conversely, mutants which did not sporulate very efficiently after removal of purine were blocked in steps $1 \mathrm{a}$ (60173), $1 \mathrm{~b}$ (60016 and 61232) and 4 (61308 and 61509). It may be significant that all Gua mutants showed significant residual growth and sporulated well whereas all Ade mutants did not.

\section{Growth and sporulation under conditions of partial purine limitation}

While the correlation between the residual growth and the spore titre observed after removal of a required purine (Fig. 3) was enticing, it could conceivably be due to chance. Therefore, sporulation was also measured in some of the more tightly blocked purine mutants under conditions in which they grew at different rates controlled by different concentrations of an adequate precursor of purine nucleotides. Adenine, adenosine, hypo- 


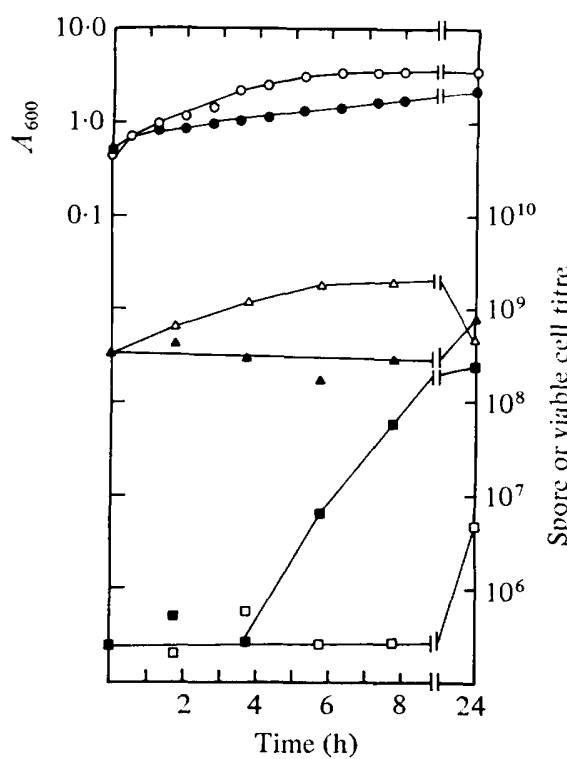

Fig. 2

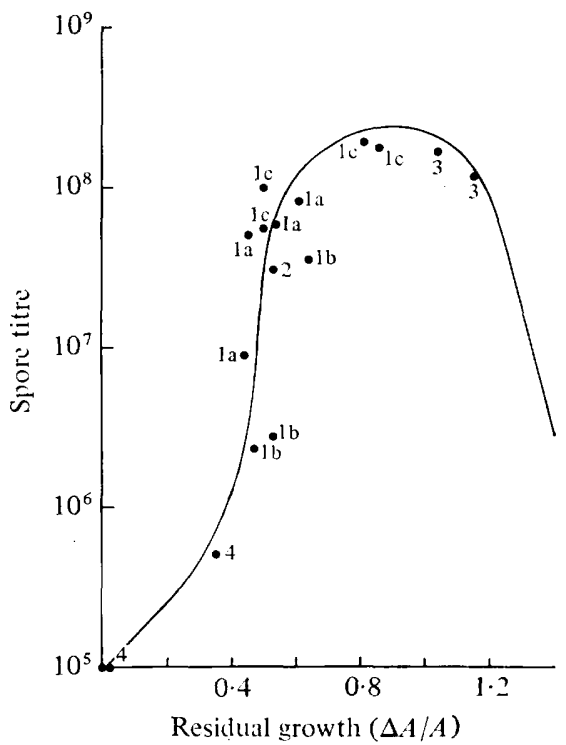

Fig. 3

Fig. 2. Growth and sporulation of a purine auxotroph. Strain 60017 was grown in synthetic medium containing $55 \mathrm{~mm}$-glucose, $50 \mu \mathrm{g}$ L-tryptophan $\mathrm{ml}^{-1}$ and $50 \mu \mathrm{g} \mathrm{L}$-histidine $\mathrm{ml}^{-1}$ in the absence $(\odot, \Delta, \square)$ or presence $(O, \Delta, \square)$ of $50 \mu \mathrm{g}$ hypoxanthine $\mathrm{ml}^{-1}: A_{600}(O, O)$; viable cell titre $(\boldsymbol{\Delta}, \Delta)$; heat-resistant spore titre $(\boldsymbol{\square}, \square)$.

Fig. 3. Growth and sporulation of purine auxotrophs in the absence of purines. Each point represents the average spore titre (measured $10 \mathrm{~h}$ after transfer to medium lacking the required purine) and the corresponding $\Delta A_{600} / A_{600}$ value (indicating residual growth in $3 \mathrm{~h}$ after transfer), as listed in Table 2. The number next to each point represents the class of biochemical block as defined in Fig. 1.

xanthine or inosine could not be used for this purpose because purine auxotrophs grew at the maximal rate until the purine was almost completely used up. The growth rate then changed within $15 \mathrm{~min}$ to the low value typical of the particular mutant in the absence of purines. Transfer to a medium containing a small amount of such a purine produced a somewhat higher spore titre than transfer to a purine-free medium, but it was difficult to produce different constant growth rates. However, when the medium was supplemented with different concentrations of AICA, different growth rates were observed for mutants blocked before AICAR (Fig. 4a). [For this and all the following experiments we used synthetic medium containing both glucose $(55 \mathrm{~mm})$ and sodium L-glutamate $(20 \mathrm{~mm})$ because the cells grew more rapidly and after a shorter lag than with glucose alone.] The effect of AICA on sporulation is shown in Fig. 4(b) for a mutant (61232) that sporulated at a low frequency in the absence of any purine (Table 2). Following growth in synthetic medium containing $300 \mu \mathrm{M}$-hypoxanthine, the cells were washed, transferred to fresh medium containing different amounts of AICA and sporulation was determined $10 \mathrm{~h}$ later. The spore titres increased with increasing AICA concentrations, reaching a maximum at 2 mM-AICA, and then decreased at higher AICA concentrations (Fig. 4b). This result demonstrates how important it was for the cells to produce nucleotides at the appropriate intermediate rate to achieve optimal sporulation in the presence of excess of other nutrients. The total viable cell titre changed comparatively little over the whole AICA concentration range. 

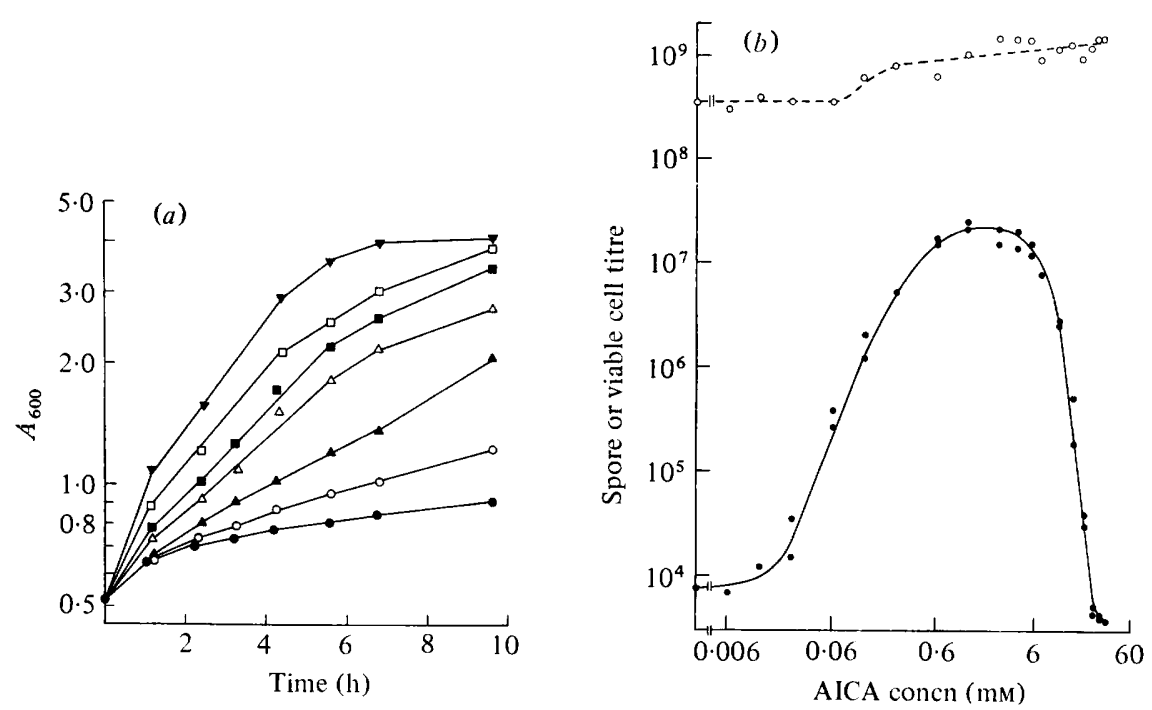

Fig. 4. Dependence of sporulation of a purine mutant on the concentration of AICA. Strain 61232 was grown overnight from a very low inoculum in synthetic medium containing 55 mm-glucose, $20 \mathrm{~mm}$-glutamate, and $300 \mu \mathrm{M}$-hypoxanthine. When the $A_{600}$ reached $0 \cdot 5$, the cells were rapidly filtered and washed on membrane filters and then resuspended in the same medium but with different concentrations of AICA. (a) Typical growth curves at AICA concentrations of $0(O), 0.25 \mathrm{~mm}(O)$, $0.62 \mathrm{~mm}(\Delta), 1.2 \mathrm{~mm}(\triangle), 2.5 \mathrm{~mm}(\square), 6.2 \mathrm{~mm}(\square)$ and $25 \mathrm{~mm}(\boldsymbol{\nabla})$. (b) Total viable cell titre $(O)$ and heat-resistant spore titre $(O) 10 \mathrm{~h}$ after resuspension $\left(t_{10}\right)$.

\section{Special behaviour of guanine auxotrophs}

All mutants requiring xanthine or guanine $(G u a A)$ or strictly requiring guanine $(G u a B)$ grew slowly and sporulated quite well when transferred to synthetic medium plus $55 \mathrm{~mm}-$ glucose and without guanine (Table 2). However, only in one strain (61306) could the usual concentrations of guanine $\left(50 \mu \mathrm{g} \mathrm{ml}^{-1}=330 \mu \mathrm{M}\right)$ prevent sporulation at $t_{10}$. Although the rate of growth of the other three mutants $(61307,61676$ and 61677) slowly increased with increasing concentrations of guanine (100 to $800 \mu \mathrm{M})$, these strains still sporulated before glucose was exhausted. Kinetic measurements for strain 61676 showed that increasing guanine concentrations caused an increasing delay of sporulation, which amounted to about $2 \mathrm{~h}$ at $300 \mu \mathrm{M}$ guanine, compared with a culture without guanine. When measured at $t_{10}$, the highest sporulation frequency (S/V 25\%) was observed with $600 \mu \mathrm{M}$-guanine. Since these mutants carried a second mutational block in the general purine pathway, the medium was supplied with hypoxanthine or adenine (at $100 \mu \mathrm{g} \mathrm{ml}^{-1}$ ) in addition to guanine. Only saturating concentrations $\left(>1 \mu \mathrm{mol} \mathrm{ml}^{-1}\right.$ ) of guanine (in addition to 735 $\mu \mathrm{M}$-hypoxanthine) prevented sporulation, measured at $t_{10}$. For the above and the following experiments the cells were inoculated into synthetic medium containing $55 \mathrm{~mm}$-glucose, $20 \mathrm{~mm}$-glutamate, $0 \cdot 1 \%(\mathrm{w} / \mathrm{v})$ vitamin-free casein hydrolysate (Difco), $735 \mu \mathrm{M}$-hypoxanthine and $1 \mathrm{~mm}$-guanosine (the casein hydrolysate prevented the otherwise pronounced clumping of the Gua mutants). When the $A_{600}$ reached 0.5 , the cells were washed (on membrane filters) in the same medium without guanosine and resuspended at the same $A_{600}$ in the medium with different amounts of guanine or guanosine.

$\left[8-{ }^{14} \mathrm{C}[\right.$ Guanine, whose fate in a culture of strain 61676 was followed by thin-layer chromatography and autoradiography of the medium, was only slowly consumed (Fig. 5a). Apart from a faint radioactive spot at the position of hypoxanthine, no other radioactive spots were detected in the medium; apparently most of the consumed guanine remained associated 

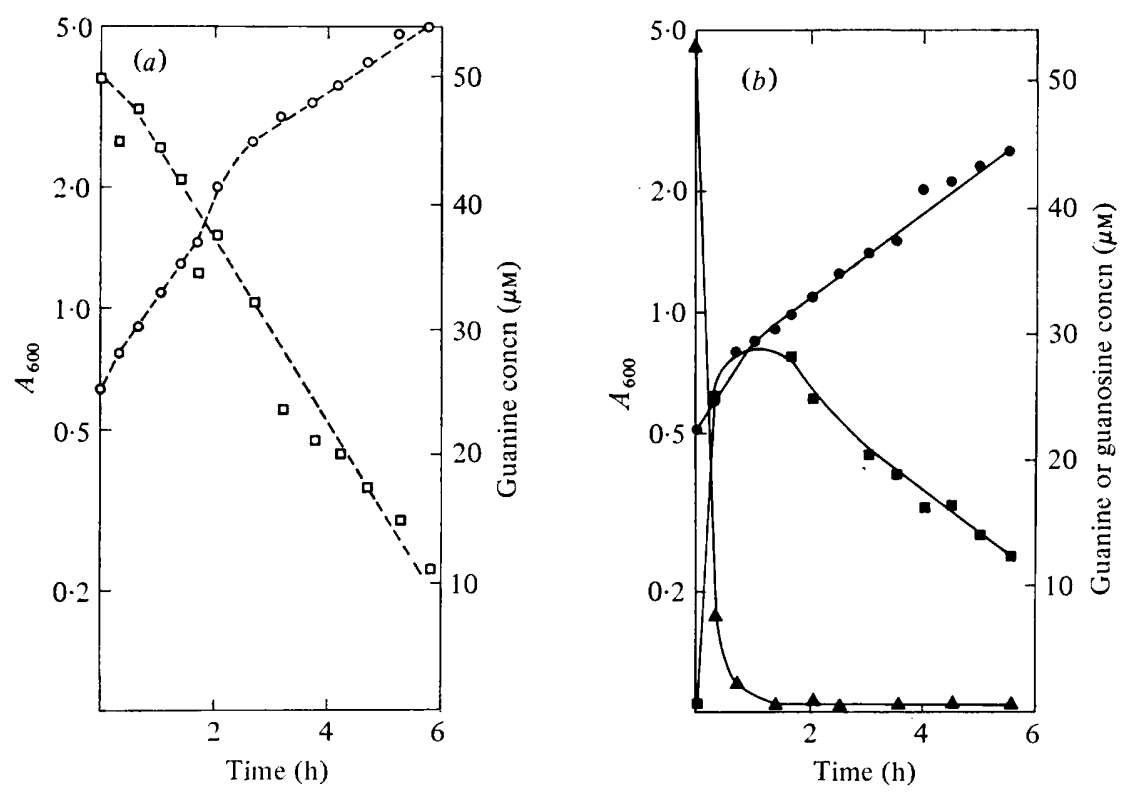

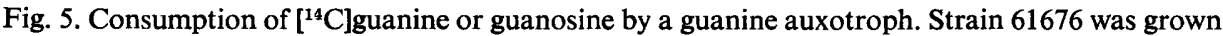
from a low inoculum in synthetic medium containing $55 \mathrm{~mm}$-glucose, $20 \mathrm{~mm}$-glutamate, $0 \cdot 1 \%$ (w/v) casein hydrolysate, $735 \mu \mathrm{M}$-hypoxanthine and $1 \mathrm{mM}$-guanosine. When the $A_{600}$ reached 0.5 , the cells were washed on membrane filters and resuspended in the same medium without guanosine. To $15 \mathrm{ml}$ suspension, $\left[8-{ }^{14} \mathrm{C}\right]$ guanine $(a)$ or $\left[\mathrm{U}-{ }^{14} \mathrm{C}\right]$ guanosine $(b)$ was added to give $50 \mu \mathrm{M}$ and $1.67 \mu \mathrm{Ci} \mathrm{ml}{ }^{-1}$. At different times the $A_{600}$ of $0.8 \mathrm{ml}$ samples was measured; the cells were then removed by centrifugation and $5 \mu \mathrm{l}$ of each supernatant was chromatographed on a thin-layer sheet which was autoradiographed, and the radiactive spots were cut out and counted. (a) Guanine $(\square) ; A_{600}(O)$.

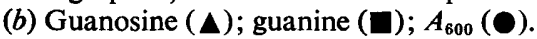

with the cells. Therefore the transport and/or conversion to GMP (via phosphoribosylpyrophosphate transferase) probably limited the rate of GMP synthesis in this Gua mutant. This effect may be due to the presence of hypoxanthine which competes with guanine.

In contrast to guanine, $0.5 \mathrm{~mm}$-guanosine prevented sporulation in all guanine mutants. This was examined in more detail in two guanine auxotrophs $(61676,61677)$. Figure $6(a)$ shows typical growth curves of one such mutant (Pur GuaA, 61676) for different initial guanosine concentrations. Following an initial rapid growth, the growth rates declined and, for the lower amounts of added guanosine, the linear growth curves were eventually parallel. At a given time, the height of these parallel lines depended on the initial guanosine concentration, indicating that guanosine was rather rapidly metabolized and used up except when its concentration was $>300 \mu \mathrm{M}$. Without any guanosine in the resuspension medium both mutants sporulated quite well (spore titres at $t_{10}$ were $1.6 \times 10^{7}$ for 61676 and $8.5 \times 10^{7}$ for 61677 ; Fig. $6 b$ ). The spore titre increased with the guanosine concentration to a maximum at about $100 \mu \mathrm{M}$-guanosine for 61676 and $50 \mu \mathrm{M}$-guanosine for 61677 (the latter strain presumably required less guanosine for optimal sporulation because it was more leaky producing more GMP de novo). The sporulation frequency (S/V) reached a maximum value of $37 \%$ for 61676 and $80 \%$ for 61677 . For higher initial guanosine concentrations the spore titre was lower and remained below $10^{2}$ if the guanosine concentration was $>300 \mu \mathrm{M}$. The spores observed at $t_{10}$ were not revertants. This was immediately apparent from the small size of the colonies on TBAB plates and was ascertained, in the case of $100 \mu \mathrm{M}$ initial guanosine, for 25 colonies: bacteria isolated from such colonies grew on guanine but not on adenine or hypoxanthine. The other two $G u a$ auxotrophs $(61306,61307)$ also sporulated well with $100 \mu \mathrm{M}$-guanosine and showed no sporulation with $1 \mathrm{~mm}$-guanosine. (Attempts to obtain 

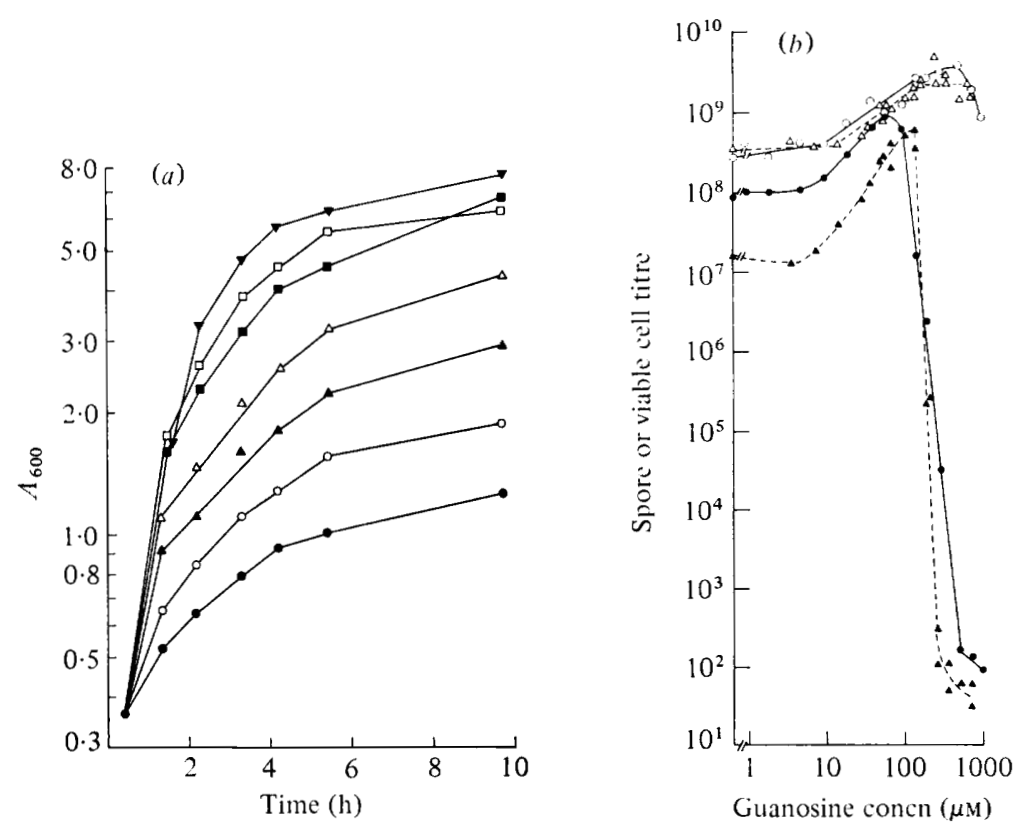

Fig. 6. Dependence of growth and sporulation of two guanine auxotrophs on the guanosine concentration. Strains 61676 and 61677 were grown overnight from a very low inoculum in synthetic medium containing $55 \mathrm{~mm}$-glucose, $20 \mathrm{~mm}$-glutamate, $0.1 \%$ (w/v) casein hydrolysate, $735 \mu \mathrm{M}$ hypoxanthine and $1 \mathrm{~mm}$-guanosine. When the $A_{600}$ reached $0 \cdot 4$, the cells were rapidly filtered and washed on membrane filters and then suspended in the same medium but with different concentrations of guanosine. (a) Typical growth curves of strain 61676 at guanosine concentrations of $0(O)$, $15 \mu_{\mathrm{M}}(\mathrm{O}), 38 \mu_{\mathrm{M}}(\mathbf{\Delta}), 71 \mu_{\mathrm{M}}(\triangle), 141 \mu_{\mathrm{M}}(\square), 265 \mu_{\mathrm{M}}(\square)$ and $707 \mu_{\mathrm{M}}(\boldsymbol{\Delta})$ ). (b) Total viable cell titre $(O, \triangle)$ and spore titre $(O, \Delta) 10 \mathrm{~h}$ after resuspension, for strains $61676(---)$ and 61677 $(-)$.

high sporulation frequencies for the $A d e$ mutants, by changing the adenine or adenosine concentration in the medium, were unsuccessful.)

To analyse the rapid metabolism and fate of guanosine, a culture of the Pur GuaA mutant (61676) was grown and washed as above and then inoculated into a medium containing $50 \mu \mathrm{M}$ [U-14 C]guanosine $\left(1.67 \mu \mathrm{Ci} \mathrm{m}^{-1}\right)$. At different times samples were centrifuged and $5 \mu \mathrm{l}$ of each supernatant was chromatographed on thin-layer plates. After autoradiography it was apparent that guanosine disappeared rapidly and a strong radioactive spot appeared at the position to which guanine (added as non-radioactive marker) chromatographed (the material was definitely not xanthine, hypoxanthine, inosine, adenine or adenosine). The spots were cut out and their radioactivities were measured; Fig. 5(b) shows how the guanosine label decreased while the label of the new spot (guanine) increased with time. The rapid initial growth in the presence of guanosine indicates that guanosine was effectively converted to GMP as that was needed for growth. But simultaneously, much of the guanosine was rapidly converted (inside the cell or on its surface) to guanine and released into the medium. The subsequent uptake and metabolism of extracellular guanine to GMP (via phosphoribosyl transferase) was so slow that the rate at which GMP and its products were then produced apparently limited the rate of growth and no longer sufficed to suppress sporulation. 


\section{DISCUSSION}

Our results demonstrate that purine auxotrophs of $B$. subtilis can sporulate in a medium containing excess ammonia, glucose and phosphate but lacking the required purine, if they are able to continue growth at a low rate due to a leaky purine mutation. If the medium contains small amounts of the required purine, which are used up before the maximum possible $A_{600}$ has been reached, the mutants sporulate somewhat better than if they are transferred to a medium without purines. The best sporulation is observed for specific guanine auxotrophs; they sporulate even in the presence of guanine, which they transport and metabolize in the presence of hypoxanthine only slowly. Guanosine, which is rapidly metabolized into another compound (probably guanine), allows optimal sporulation if its initial concentration is 50 to $100 \mu \mathrm{M}$ (depending on the Gua mutation); at high concentrations ( $>500 \mu \mathrm{M}$ ), guanosine is not used up by the time growth stops and no sporulation is observed for an extended time.

Non-leaky purine auxotrophs can also sporulate in excess ammonia, glucose and phosphate if they are continuously supplied with small amounts of a precursor of purine nucleotides entering the purine pathway after the mutational block. We found it easiest to regulate this purine supply by using AICA for which different and rather high concentrations in the medium produced different rates of growth; apparently, the cellular rate at which the phosphorylated compound AICAR is synthesized is proportional to the extracellular concentration of AICA. Adenine, hypoxanthine or their nucleosides could not be used in this way because even low concentrations of these compounds allowed growth at the maximum rate until the compound was virtually exhausted. [An exception is the Pur mutant 61305 which sporulates even in the presence of hypoxanthine $(300 \mu \mathrm{M})$ presumably because hypoxanthine is not rapidly converted to IMP in this strain, similar to the effect of guanine in the abovementioned guanine mutants; this effect was not further investigated.]

Our results suggest that those purine mutants of B. cereus (Levisohn \& Aronson, 1967) and $B$. megaterium (Elmerich \& Aubert, 1975) which can sporulate without any purine in the presence of rapidly metabolizable nitrogen and carbon sources may either be leaky in their purine deficiency or may accumulate enough precursors to supply the required purines at a slow rate during development. Furthermore, the one reported glutamine-requiring mutant of $B$. megaterium able to sporulate in the absence of glutamine (Elmerich \& Aubert, 1975) may be leaky in its glutamine deficiency so that it can supply the purine nucleotides, whose synthesis depends on glutamine, at the necessary slow rate.

In contrast to the results of Elmerich \& Aubert (1975) with B. megaterium, we have found in $B$. subtilis that not only mutants blocked between PRPP and AIR but also mutants blocked in later steps of the purine pathway, including the GMP branch, can sporulate well in the presence of excess ammonia, glucose and phosphate when the required purine is removed. This difference could indicate a basic difference in the mechanisms controlling sporulation of $B$. megaterium and $B$. subtilis. It appears to us more likely that the purine auxotrophs of $B$. megaterium isolated by these authors as deficient in step la of purine synthesis (Fig. 1) were of necessity leaky because the isolation medium did not contain thiamin, whose synthesis requires AIR. In contrast, the purine auxotrophs blocked after AIR might be too stringent (non-leaky) to allow sporulation in the absence of any purine in the medium. This issue could be resolved by measuring the sporulation of such mutants in the presence of a nucleotide precursor such as AICA whose concentration in the medium controls the intracellular concentration of nucleotides.

Although sporulation was induced here under conditions of slow growth, i.e. continued division of some cells in the population, such growth is not necessary for differentiation, as is demonstrated by the fact that cells sporulate at the end of growth in the usual sporulation media. However, the continued slow supply of nucleotides is necessary for DNA synthesis at the beginning of sporulation and for continued mRNA synthesis required to produce the multitude of sporulation-specific proteins. In some organisms, such as B. megaterium grown 
under appropriate conditions, all nucleotides can be produced by turnover and de novo synthesis utilizing intracellular carbon sources (poly- $\beta$-hydroxybutyrate). In the smaller cells of $B$. subtilis, some nucleotides clearly have to be synthesized during sporulation either de novo using extracellular carbon sources or by salvage synthesis, as was shown by the use of auxotrophic mutants under the usual sporulation conditions (Freese et al., 1974) and is evident from the results presented here.

Presumably, the Bacillus species has evolved control mechanisms regulating the proper supply of nucleotides from slowly metabolizable carbon sources at the time at which growth has virtually ceased. Under our growth conditions, in the presence of glucose, nucleotides are formed at such a rapid rate that sporulation normally remains suppressed. If this synthesis is partially reduced by inhibitors (Mitani et al., 1977; Freese et al., 1978; Heinze et al., 1978) or by limiting the purine supply to auxotrophic mutants as done here, sporulation is initiated in some cells while others, being at a different stage of their growth cycle, having larger amounts of purine transport molecules or being different in size, continue to divide (at least for some time). While one can thus understand the stochastic distribution of cells producing symmetric and asymmetric septa, we were surprised that partial purine, and especially guanine, starvation alone suffices to allow the sporulation development to go to completion. (This requires, for example, that the asymmetric septum is not filled with large amounts of murein.)

The studies using metabolic inhibitors indicate that sporulation results from a reduction in the synthesis of AMP or GMP and their metabolic products. But it is important to note that these syntheses are interdependent because ATP is required for GMP synthesis and GTP for AMP synthesis. In fact, other results from this laboratory show that hadacidin, which specifically inhibits the de novo synthesis of adenine nucleotides and inefficiently induces sporulation, causes a decrease of all nucleoside triphosphates including GTP. In contrast decoyinine, which specifically inhibits the de novo synthesis of guanine nucleotides, or guanine deficiency produced in a guanine auxotroph (both conditions that efficiently produce sporulation), decrease the concentration of guanosine - but not adenosine - nucleotides (Lopez, Marks \& Freese, Biochimica et biophysica acta, in the Press). Furthermore, all our specific adenine auxotrophs sporulate poorly on removal of adenine whereas all our specific guanine auxotrophs sporulate well (with or without guanine) after guanosine has been used up. Thus, the decrease of guanine nucleotides may be essential for the initiation of sporulation. It remains unresolved whether this decrease causes the decrease of a repressor or the production of an inducer of sporulation, or whether it generates a new balance in the relative rate of the syntheses of RNA and protein on the one hand and of other polymers (membrane) on the other.

John E. Heinze was on leave from the Department of Biology, Oklahoma Baptist University, during the course of these experiments and gratefully acknowledges the University's support and encouragement.

\section{REFERENCES}

Bohin, J. P., Rigomier, D. \& Schaeffer, P. (1976). Ethanol sensitivity of sporulation in Bacillus subtilis: a new tool for the analysis of the sporulation process. Journal of Bacteriology 127, 934-940.

Bratton, A. C. \& Marshall, E. K., JR (1939). A new coupling component for sulfanilamide determination. Journal of Biological Chemistry 128, 537-550.

Burke, W. F. \& SpIzizen, J. (1977). Selective inhibition of Bacillus subtilis sporulation by acridine orange and promethazine. Journal of Bacteriology 129, 1215-1221.

Coddington, A. (1970). Guanosin. In Methoden der Enzymatischen Analyse, vol. III, pp. 1862-1865.
Edited by H. U. Bergmeyer. Weinheim: Verlag Chemie.

Demain, A. L. \& Shigeura, H. T. (1968). Dependence of diaminopurine utilization on the mutational site of purine auxotrophy in Bacillus subtilis. Journal of Bacteriology 95, 565-571.

Elmerich, C. \& AuberT, J. P. (1975). Involvement of glutamine synthetase and the purine nucleotide pathway in repression of bacterial sporulation. In Spores VI, pp. 385-390. Edited by P. Gerhardt, R. N. Costilow \& H. L. Sadoff. Washington: American Society for Microbiology.

Freese, E. (1976). Metabolic control of sporulation. In Spore Research 1976, pp. 1-32. Edited by 
A. N. Barker, G. W. Gould \& J. Wolf. London: Academic Press.

Freese, E., Ichikawa, T., Oh, Y. K., Freese, E. B. \& Prasad, C. (1974). Deficiencies or excesses of metabolites interfering with differentiation(vitamin deficiency, glycerol-phosphate dehydrogenase/ glucose-6-phosphate/glycerolphosphate). Proceedings of the National Academy of Sciences of the United States of America 71, 4188-4193.

Freese, E., Heinze, J., Mitani, T. \& Freese, E. B. (1978). Limitation of nucleotides induces sporulation. In Spores VII, pp. 277-285. Edited by G. Chambliss \& C. Vary. Washington: American Society for Microbiology.

Hanson, R. S., Peterson, J. A. \& Yousten, A. A. (1970). Unique biochemical events in bacterial sporulation. Annual Review of Microbiology 24, 53-90.

Heinze, J. E., Mitani, T., Rich, K. E. \& Freese, E. (1978). Induction of sporulation by inhibitory purines and related compounds. Biochimica et biophysica acta (in the Press).

Iijima, T., Diesterhaft, M. D. \& Freese, E. (1977). Sodium effect of growth on aspartate and genetic analysis of Bacillus subtilis mutant with high aspartase activity. Journal of Bacteriology 129, 1440-1447.

Ito, J. \& SpIzizen, J. (1973). Genetic studies of catabolite repression in sensitive sporulation mutations of Bacillus subtilis. In La Regulation de la Sporulation Microbienne (Gif-sur-Yvette, editions of C.N.R.S.), pp. 81-82. Paris: C.N.R.S.

JORGENSEN, S. (1970). Hypoxanthine and xanthine. In Methoden der Enzymatischen Analyse, vol. III, pp. 1874-1878. Edited by H. U. Bergmeyer. Weinheim:Verlag Chemie.

Keilman, G. R., Burtis, K., Tanimoto, B. \& Doi, R. H. (1976). Effect of netropsin on the depression of enzymes during growth and sporulation of Bacillus subtilis. Journal of Bacteriology 128, 80-85.

Kunst, F., Pascal, M., Lepesant-Kejzlarova, J., Lepesant, J. A., Billault, A. \& Dedonder, R. (1974). Pleiotropic mutations affecting sporulation conditions and the synthesis of extracellular enzymes in Bacillus subtilis 168. Biochimie 56, 1481-1489.

Levisohn, S. \& Aronson, A. I. (1967). Regulation of extracellular protease production in Bacillus cereus. Journal of Bacteriology 93, 1023-1030.

MAGASANIK, B. (1962). Biosynthesis of purine and pyrimidine nucleotides. In The Bacteria, pp. 295334. Edited by 1. C. Gunsalus \& R. Y. Stanier. New York: Academic Press.

Mitani, T., Heinze, J. E. \& Freese, E. (1977). Induction of sporulation in Bacillus subtilis by decoyinine or hadacidin. Biochemical and Biophysical Research Communications 77, 1118-1125.

RAMALEY, R. F. \& BuRdEN, L. (1970). Replacement sporulation of Bacillus subtilis 168 in a chemically defined medium. Journal of Bacteriology 101, 1-8.

ReysSeT, G. \& AUberT, J. P. (1975). Relationship between sporulation and mutations impairing glutamine synthetase in Bacillus megaterium. Biochemical and Biophysical Research Communications 65, 1237-1241.

Rhaese, H. J., Hoch, J. A. \& Groscurth, R. (1977). Studies on the control of development: isolation of Bacillus subtilis mutants blocked early in sporulation and defective in synthesis of highly phosphorylated nucleotides. Proceedings of the National Academy of Sciences of the United States of America 74, 1125-1129.

Rogolsky, M. \& Nakamura, H. T. (1974). Sensitivity of an early step in the sporulation of Bacillus subtilis to selective inhibition by ethidium bromide. Journal of Bacteriology 119, 57-61.

SCHAEFFER, P. (1969). Sporulation and the production of antibiotics, exoenzymes and exotoxins. Bacteriological Reviews 33, 48-71.

Sugae, K. \& FreEse, E. (1970). Requirements for acetate and glycine (or glycine) for sporulation without growth of Bacillus subtilis. Journal of Bacteriology 104, 1074-1085.

Young, F. E. \& Wilson, G. A. (1975). Chromosomal map of Bacillus subtilis. In Spores VI, pp. 596-614. Edited by P. Gerhardt, R. N. Costilow \& H. L. Sadoff. Washington: American Society for Microbiology. 